\title{
Delinquent Development in Dutch Childhood Arrestees: Developmental Trajectories, Risk Factors and Co-morbidity with Adverse Outcomes during Adolescence
}

\author{
L. van Domburgh • R. Vermeiren • A. A. J. Blokland • \\ Th. A. H. Doreleijers
}

Published online: 14 August 2008

(C) The Author(s) 2008. This article is published with open access at Springerlink.com

\begin{abstract}
Heterogeneity of re-offending patterns was studied in a group of 287 male early onset offenders who were first arrested before age 12. By combining data on the frequency and severity of offending as registered by the police over a 5-year follow-up period, three delinquent trajectories were identified; low, escalating, and high level re-offenders. Predicting group membership by individual and environmental characteristics known to the police at the time of the first arrest proved difficult. Compared to low level re-offenders, escalators were older and more often came from disadvantaged neighborhoods. High level re-offenders were also older at onset, more often had a non-Western ethnic background, and initially committed more vandalism. Furthermore, at the first police encounter, the police reacted more severely towards those who later became high level re-offenders. Finally,
\end{abstract}

L. van Domburgh $(\bowtie)$

Department of Child and Adolescent Psychiatry,

VUMC Medical Center,

P/a De Bascule, P.O. Box 303, 1115 ZG Duivendrecht,

The Netherlands

e-mail: 1.vandomburgh@debascule.com

R. Vermeiren

Department of Child and Adolescent Psychiatry, Curium-LUMC,

Leiden, The Netherlands

R. Vermeiren • T. A. H. Doreleijers

Department of Child and Adolescent Psychiatry,

VUMC Medical Center,

Amsterdam, The Netherlands

A. A. J. Blokland

Netherlands Institute for the Study of Crime

and Law Enforcement (NSCR),

Leiden, The Netherlands high and escalating re-offenders more often had other adverse outcomes, such as criminal victimization and Child Welfare Agency involvement.

Keywords Early onset - Delinquency trajectories · Persistence $\cdot$ Police contacts

\section{Introduction}

Childhood onset delinquents are known to be at high risk for developing persistent and serious offending careers (Loeber and Farrington 2000; Espiritu et al. 2001; Moffitt 1993; Krohn et al. 2001). Specifically, a police arrest during childhood was shown to predict frequent and persistent reoffending (Snyder 2001; Krohn et al. 2001). Still, despite indications of continuity, discontinuity is substantial as well, as not all childhood arrestees grow up to be persistent offenders (Krohn et al. 2001). In order to better target early intervention efforts at those who carry the highest risk of prolongation, factors within the subgroup of childhood onset delinquents that help to classify future persisters from desisters and non-recidivists need being identified. To this end, this study investigates recidivism over a 5-year followup period in a sample of juveniles first arrested by the Dutch police under the age of $12 .^{1}$ Our aim is to examine whether distinct delinquency trajectories can be identified based on the frequency and severity of offending and to

\footnotetext{
${ }^{1}$ Although according to Dutch law, children are not criminally liable below age 12 , children detained by the police due to illegal behavior are called arrestees in this paper. Children are also called arrestees if not taken to the police station but reprimanded on the street. Status offences are not included in this definition.
} 
examine whether these trajectories can be predicted by the child's individual and environmental risk factors and offence characteristics as registered by the police.

\section{Developmental Theories on Early Onset Delinquency}

While most youths seem to only temporarily engage in delinquency during adolescence and refrain from committing more serious offences, a small proportion (6-7\%) persists in offending well beyond adolescence. This group offends at a high rate and commits serious crimes, all too often interpersonal violence (Moffitt 1993). An early onset of antisocial behavior is an important risk factor of such persistent, high frequency and serious delinquent trajectory (Moffitt 1993; Loeber and Farrington 2001; Patterson et al. 1998; Lahey and Waldman 2005). Only recently, academics have started focusing on subgroup specific delinquent trajectories and related individual and environmental differences within the early onset offender group. While some developmental theories delineate an etiologically distinct subgroup of early onset offenders (Moffitt 1993; Patterson 1996), others argue that a higher risk of chronic offending in this early onset group results from a higher prevalence of and a longer exposure to risk factors (e.g. Loeber et al. 1998; Gottfredson and Hirschi 1990).

In what is currently one of the most referenced developmental typologies of offending, Moffitt (1993) asserts that an early onset of antisocial behavior results from a combination of neuropsychological difficulties and inadequate parent-child interaction. Given that early onset delinquency does not originate from peer group dynamics, these youths are more likely to engage in solo-as opposed to group - offending. In later elaborations of the taxonomic model, Moffitt et al. (2002) distinguished early onset high level chronics from low level chronics, while both groups show prolonged delinquent involvement, severity is at different levels. Isolating pathologies such as depression are expected to differentiate both groups, with the low level group carrying most problems. On the whole, high levels of individual impairment of children on either of these persistent trajectories predispose them to disproportionately engage in serious and person-orientated offending.

Similarly distinguishing childhood and adolescence onset delinquents Patterson et al. (1998) described disruptive family processes as a major cause of early onset offending. Such processes lead to childhood antisocial behavior and shape peer interaction patterns in late childhood and adolescence. Disruptive peer processes and engagement with antisocial peers increasingly lead to offending outside the home and eventually to chronic offending (Patterson 1996; Patterson et al. 1998). Contrary to Moffitt's taxonomy, the Patterson typology thus expects early onset persistent offenders to mainly engage in group offending. Finally, Lahey and Waldman (2005) expect those children showing childhood onset problem behavior but living in more adaptive social environments to improve during childhood and not to be at high risk of developing persistent and serious delinquent trajectories.

Among the dimensional theories of offending, the developmental pathway model of Loeber et al. (1998) focuses on offence specific pathways which lead to distinct forms of serious offending. Serious offending at an earlier age indicates being further along a developmental pathway and therefore being at higher risk of persisting in serious offending. In contrast, Gottfredson and Hirschi (1990) do not predict that frequent offenders will be more likely to become serious offenders than less frequent offenders. Finally, there are developmental theories that stress offenders' behavioral plasticity and the influence of endogenous factors on the development of their criminal careers (Sampson and Laub 2005; Thornberry and Krohn 2001). Under the assumption that occurrences of these contextual changes are to a considerable degree independent of the child's individual characteristics, these authors seriously question the value of individual risk factors in a priori predicting longterm delinquent development (Sampson and Laub 2005).

\section{Prior Research on Early Onset Re-offending}

While an early onset was found to be associated with later delinquency (for a review see: Loeber and Farrington 2001), few studies have specifically focused on differences in outcomes among early onset offenders. This may carry relevance, as a considerable proportion of early onset children was reported to desist in adolescence (e.g. Raine et al. 2005; Stouthamer-Loeber et al. 2008; Moffitt et al. 2002). Further, these studies defined subgroups of offenders a priori based on existing theories, possibly overlooking naturally occurring subgroups. With the advance of latent growth curve models in developmental criminology, more recent studies were able to identify several longitudinal delinquent trajectories (see Piquero 2008 for a review). The few studies that included both childhood and adolescent offending were able to identify trajectories generally referred to as: (1) a group of early onset sporadic offenders; (2) a group of early onset persisters or chronics; and (3) a group of early onset desisters (Odgers et al. 2007; Chung et al. 2002; Fergusson and Horwood 2002; Nagin and Tremblay 1999). However, only Chung et al. (2002) used offending as a measure of childhood antisocial behavior, while others used parent and/or teacher reports of conduct problems or aggression (Odgers et al. 2007; Nagin and Tremblay 1999; Fergusson and Horwood 2002). In addition, all of these studies focused on offending trajectories as occurring in the general population instead of re-offending 
trajectories in a population of known early onset offenders. Since the overall proportion of early onset offenders in the general population is low, this may have precluded meaningful differentiation within early onset offenders subgroups. Notwithstanding these limitations, findings do seem to suggest that distinctive subgroups of early onset offenders can be identified.

Risk factors differentiating among subgroups of early onset offenders are, however, scarce and inconsistent. For instance, some studies found no early childhood differences between persisting and desisting offenders with regard to individual and environmental characteristics (Moffitt et al. 2002; Chung et al. 2002). Other studies found early onset re-offenders as compared to desisters and sporadic reoffenders to originate more often from dysfunctional families residing in adverse urban neighborhoods (e.g. Odgers et al. 2007; Fergusson and Horwood 2002; Patterson et al. 1998; Farrell et al. 2005).

Studies on the predictive value of first offence characteristics of early onset offenders have also been inconclusive. For instance, although an early age of onset seems to be predictive of frequent and severe adolescent re-offending within a population of childhood onset offenders (Piquero and Chung 2001; Broidy et al. 2003; Chung et al. 2002; Lipsey and Derzon 1998), this finding did not hold for official violent re-offending (Krohn et al. 2001). In addition, although numerous studies have stressed the predictive value of childhood interpersonal violence, some studies have shown childhood non-serious (covert) delinquent acts to be equally predictive of re-offending (Broidy et al. 2003; Chung et al. 2002; Lipsey and Derzon 1998). Although some probable risk factors have been identified, additional studies using various samples are warranted to further establish and generalize their value.

Finally, children following distinct re-offending trajectories may differ in other detrimental outcomes that further limit the potential to develop into healthy functioning individuals. In adolescence, serious and persistent offenders are at heightened risk to become victims and witnesses of violence themselves, show higher rates of status offences, and experience individual and family difficulties (e.g. Loeber and Farrington 2001; Lauritsen et al. 1991). On the other hand, Moffitt et al. (2002) found no differences in other negative outcomes such as psychosocial difficulties and unemployment in late adolescence and early adulthood between high-frequent and low-frequent persistent childhood onset offenders. To our knowledge, no other studies specifically looked into differences in adolescent detrimental outcomes between subgroups of early onset offenders. If offending trajectories of childhood onset delinquents are indeed related to these detrimental outcomes, this would further underline the importance of an early identification of childhood delinquents at risk of progressing along the persistent pathway.
Focus of the Current Paper

The current research expands upon the literature on juvenile delinquency in a number of ways. First, this study will specifically focus on patterns of recidivism in juveniles who were first arrested below age 12, which constitutes the age of legal responsibility in most European countries. Until now, studies using police data mostly pertain to juveniles that have already reached the age of criminal responsibility. The Dutch police registration system includes children of all ages, which allows focusing on the youngest group. Second, this study's starting point is children who have already been arrested, which gives us the opportunity of sub-classifying developmental pathways within the group of early onset delinquents. As most studies and theories are based on general population samples, factors differentiating persistent form desisting delinquents cannot be assumed to similarly predict outcome within the early onset offender group. Finally, prior studies that do focus on high risk youth are often limited in other ways, for example by only pertaining to white, lower class delinquents.

Building on prior theory and research, this paper first examines whether distinct delinquency trajectories can be identified using re-arrest data of a sample of boys who were arrested for the first time before reaching the age of 12 . Next it addresses the extent to which these delinquency trajectories are differentially predicted by individual risk factors and characteristics of the delinquent act at onset. Finally, we test whether other adolescent outcome markers, such as out-home placement, criminal victimization, and domestic problems, differ between youths following different delinquency trajectories. Based on Moffitt's taxonomy and other typological theories, we expect that at least three trajectories can be identified within our sample of early onset delinquents: (1) a high level persistent group, which is expected make up a much larger share of the sample compared to that found in prior population studies due to the high risk nature of the current sample; (2) a low level chronic group, equally persistent in delinquency, but at significantly lower frequencies; and (3) a low level or desisting trajectory of children who were only arrested once as a child without it leading to a delinquent career. Compared to their persistent counterparts, these desisting childhood onset delinquents are expected to originate from more adaptive, higher status environments.

Delinquent trajectories of persistent childhood onset offenders are hypothesized to contain serious as well as person orientated offences, while childhood violence is expected to predict chronicity. In addition, childhood solo-as compared to group offending is expected to be a risk factor for persistence in delinquency. Due to processes of cumulative disadvantage, persistent groups are expected to show higher levels of detrimental outcomes during adolescence. 


\section{Method}

Participants

Subjects were 287 boys below age 12 who were registered for the first time by the police for committing an offence in the first few months of 2000 (Utrecht and GelderlandMidden police districts) or the first few months of 2001 (Rotterdam-Rijnmond police district). Mean age at first police encounter was $10.04(\mathrm{SD}=1.16)$, with an age range between 5.01 and 11.99 years. An offence was defined as behavior that could have been prosecuted or fined if displayed at the age of 12 years or older. Local police registration systems were used for this purpose, as individuals of all ages are registered by local police in the Netherlands. In order to include children from both urban and rural regions, three different police regions in The Netherlands were sampled (127 childhood arrestees from the predominantly urban Rotterdam-Rijnmond region, 76 from the combined urban-rural Utrecht region, and 84 from the predominantly rural Gelderland-Midden region).

\section{Procedure}

In order to include all first-time registered delinquent children, registrations of juveniles below the age of 12 were manually checked to determine eligibility. Children not yet legally admitted to the Netherlands were excluded because follow-up may be hampered due to high mobility (moving is frequently ordered by authorities) and possible extradition during the follow-up period. For all eligible children, various registration systems were checked on variables of interest, including local police records, Child Welfare Agency (Raad voor de Kinderbescherming) records and records of the Dutch agency responsible for diversion projects (Bureau Halt). Data were gathered until March 2005. As a result the maximum follow-up differed between those included from 2000 and those included from 2001. Ninety-two percent were followed up for at least 4.5 years and $62.5 \%$ for at least 5 years. The study was officially approved by the Dutch Ministry of Justice.

\section{Dependent Measures}

\section{Frequency of Re-offending}

Frequency of re-offending was based on all offending behavior registered by the police. This also included information on offending behavior in which the specific role of the subject was less clear (e.g. as a member of a group that displayed offending behavior), registration of reports by third parties (e.g. school reports on violent thefts that were dealt with by the school), unsuccessful attempts at offending, and finally highly suspicious behavior (e.g. repeatedly hanging around at parking lots that had recently had cars broken into). Frequency was computed per half year period after the first arrest.

\section{Combined Frequency and Seriousness Measure}

Although frequent offenders are generally serious offenders, some frequent offenders are not serious offenders while some serious offenders are not frequent offenders (Tolan and Gorman-Smith 1998). Including measures of offense seriousness allows researchers to distinguish among offenders who have engaged in a moderate number of offenses by taking into account the gravity of each offense from those who offended often but with minor severity (Chung et al. 2002; Hoeve et al. 2007). Although a combined measure has its own limitations, for instance a score of 8 at a particular time period could be achieved by (a) eight level 1 offenses or (b) two level 4 offenses, we feel using a combined measure adds value to the analysis. Using either only count data or seriousness scores would in our eyes unjustly exacerbate differences between these two offence patterns. Therefore, a combined measure of frequency and seriousness was created by computing a sum score of the seriousness assigned to every registration of the individual per half year period.

In order to assign a level of seriousness to every registration, a classification of Seriousness of Early Police Registration (SEPR) was developed. The SEPR is an adaptation of the General Level of Seriousness Classification as developed by Loeber et al. (2008). The following adaptations from the original classification were made: (1) verbal aggression, and all non-victimizing delinquent behavior (such as trespassing, and using fire crackers outside the legally appointed period of time) were added to the classification and scored as level 1.

(2) Mild aggression such as threat of bodily harm was added to the classification and scored as level 2. (3) Physical fighting without and with bodily harm was added and scored at levels 3 and 4, respectively.

This resulted in five levels of seriousness in the SEPR:

Level 1 Minor delinquency at home, minor verbal aggression, and rule breaking.

Level 2 Minor delinquency outside the home, e.g. shoplifting and minor vandalism.

Level 3 Moderate delinquency, e.g. fighting without bodily harm, vandalism and theft.

Level 4 Serious delinquency, e.g. breaking and entering, serious arson and vehicle theft.

Level 5 Very serious delinquency, e.g. sex offences, aggravated assault, and robbery. 
If a specific police registration included behaviors of different degrees of seriousness, the behavior that scored highest on the SEPR was used to define the registration seriousness level. Although inter-rater consensus was high (ICC $=0.84$ in a two way mixed effect model with absolute agreement), consensus scores from the consensus meeting were used for further analyses to maximize reliability.

\section{Predictors}

\section{First Offence Characteristics}

First offence characteristics included were type of offending, seriousness, co-offending, and intervention by the police. Type of offending was classified into violence (19.2\%), theft (23.3\%), property damage (35.2\%), and mischief $(22.3 \%)$. Mischief consisted of behavior that was aimed at annoying others and at rule breaking without explicit intent to victimize others (e.g. driving without a helmet and trespassing). Violent offences included both verbal and physical violence. Co-offending was defined as offending with at least one other person. Age differences between subject and co-offenders were dichotomized into older co-offenders ( $\geq 4$ years older) versus the rest.

Intervention by the police was based on police reports and divided into intervention with the child and intervention with the parent. Regarding interventions with the child:

- First, no intervention was defined as the child not having been in contact with the police, e.g. because the police record was based on a report of theft by the school and the school itself had handled the case.

- Second, the child could have been stopped and warned by the police on the street.

- Third, the child could have been taken to the police station.

Regarding follow-up with parents: parents could either have been notified by the police of the behavior of their child or not. After a police encounter, children below age 12 can be sent to a voluntary program (STOP) provided by the Dutch agency responsible for diversion projects. The diversion project's records were checked for STOP programs carried out following the first police encounter.

\section{Socio-demographics}

According to the Dutch definition, a child has a non-Western ethnic background if the child himself or one of his parents is born in a non-Western country (de Heeten and Verweij 1993). Non-Western ethnicity in this study was based on country of birth of the child (if not the Netherlands) or on family name because names of most non-Western minority ethnic groups are easily recognizable. When a specific family name was common both in the Netherlands and in a foreign country, ethnicity was scored as 'unknown'. Since intercultural marriages of a foreign woman with a Dutch man (in which case the child is likely to have a Dutch family name) are rare, this method will be accurate in the vast majority of the cases (Statistics Netherlands 2001). ${ }^{2}$

\section{Neighborhood Characteristics}

Postal codes were used to determine the SES and urbanization level. The postal code classification of SES is available in quintiles based on mean income, employment, and education (Knol 1998; Social and Cultural Planning Office of the Netherlands 2002). For this study, the scores were dichotomized into a low SES variable by contrasting $1-2$ to $3-5$.

Urbanization level data from Statistics Netherlands (2006) are based on the number of households per $\mathrm{km}^{2}$ : ranging from Level 1 'no-urbanization: less than 500 households per $\mathrm{km}^{2}$, to Level 5 'very high urbanization: 2,500 or more households per $\mathrm{km}^{2}$. For this study, the scores were dichotomized into a high urbanization variable by contrasting levels $4-5$ to $1-3$.

\section{Victim or Witness Registrations and Child Welfare Agency involvement}

Local police reports on being victimized or witnessing a crime and reports on domestic problems and status offences (e.g. running away) were included. Four dichotomized variables were constructed: victim of delinquency outside the home, witness to delinquency outside the home, reports on domestic problems, and reports on status offences.

In addition, The Child Welfare Agency database was searched for any civil law reports regarding the (threatened) development of the juvenile. The reports can be based on negative family circumstances such as domestic violence, on behavioral problems of the child, or on a combination of both. Since the aim is to study co-occurring detrimental outcomes, files based solely on delinquent behavior as reported by the police were excluded.

\section{Statistical Analyses}

We use a semi-parametric group-based model to describe the course of police contacts across age for our sample.

\footnotetext{
${ }^{2}$ This method will at most have misclassified $2.8 \%$, but it is highly unlikely that the percentage is this high considering the ethnic backgrounds of foreign women marrying Dutch men. Intercultural marriages between a Dutch man and a non-Western woman mostly involve Asian or Russian woman. Asians are underrepresented in the crime records (Statistics Netherlands 2001).
} 
Conventional growth curve models describe developmental variation in terms of variance around the average growth within the population. This approach makes intuitive sense when describing unidirectional patterns of growth like vocabulary expansion in toddlers, but is less suited when development is believed to be more multifarious. Groupbased models on the other hand approximate individual developmental variation by a number of discreet groups. As in growth curve models, the outcome variable is linked to age by some polynomial function, but unlike growth curve models, the group-based model allows the parameters of this function to vary freely across groups so that the estimated course of development for each group can be very different both in level and time path. In addition to the trajectories themselves, the group-based model produces a probability of membership for each of the distinguished trajectory groups for each individual in the sample. ${ }^{3}$ These probabilities can be used for descriptive purposes by assigning each individual to the trajectory group for which his posterior probability of group membership was highest. The Bayesian Information Criterion (BIC) can be used as a formal indicator of the optimal number of groups so that no a priori assumptions on this point are necessary. High classification accuracy when assigning individuals to trajectory groups - as is indicated by the average probability of class membership across all individuals assigned to each class approaching 1 -also indicates the model fits the date well. Nagin (2005) mentions additional criteria that can be used to assess model fit. Finally, the group-based model can be augmented to include multiple risk factors thought to be associated with the probability of trajectory group membership. The association of these risk factors with trajectory group membership is estimated jointly with the trajectories themselves, so that uncertainty in trajectory membership is taken into account.

Here, group-based modeling as first developed by Nagin and Land (1993) was applied using the SAS-macro (Jones and Nagin 2007). ${ }^{4}$ A quadratic function was used to link information on police contacts to age. We estimated models from one to eight groups. Models were estimated for the dependent variables 'frequency' and 'frequency times seriousness'. In order to test whether the registrations in which the specific role of the subject was not clear did not substantially alter the identified models, models were also conducted for re-arrest data only. These analyses produced a similar result with the combined models having more statistical power. Therefore only the models including all registrations of

\footnotetext{
$\overline{{ }^{3} \text { The reader }}$ is referred to Nagin (1999, p. 149) on the way to calculate these group membership probabilities.

${ }^{4}$ For a more detailed account of these models we refer to Nagin (2005).
}

offending were described in the "Results" section. Given the age of the sampled youths, incarceration was rare and of short duration, so it was not controlled for in the analyses.

As described above, the association of risk factors with trajectory group membership was estimated jointly with the trajectories themselves, so that uncertainty in trajectory membership is taken into account. This procedure uses a reference group against which all other groups are compared. Here, the re-offender group that was lowest in seriousness and frequency of offending was taken as the reference group. As post hoc analyses, Wald tests were run to test for differences between the other groups. Finally, in order to test for differences between groups in co-occurring adverse outcomes, $\chi^{2}$ tests were conducted. Post-hoc bivariate group comparisons using $\chi^{2}$ were conducted at the 0.05 significance level. For this purpose, all subjects were assigned to the trajectory group of their highest probability. SPSS 12.0 was used for these analyses.

\section{Results}

\section{Re-offending Trajectories}

Using the trajectory method, we were able to assess whether early onset offenders follow distinct trajectories of police registered re-offending. First, using frequency of re-offending as the response variable and using the BIC criterion to identify the optimal fit, a three trajectory model was found to best describe the data (Fig. 1 and Table 1). The average posterior class membership probabilities for this three-class solution ranged from 0.91 to 0.93 , indicating good model fit. ${ }^{5}$ The first trajectory group consisted of children who did not or only sporadically re-offend during the follow-up period. This low level re-offending trajectory group was estimated to make up $64.8 \%$ of the sample. The second trajectory group showed an upward slope in recidivism frequency during the follow-up period. This escalating trajectory group was estimated to make up $30.0 \%$ of the sample. On average, escalators were reregistered by the police more than seven times during the 5-year follow-up. Escalators were predominantly registered for theft offences. Finally, a small proportion of the sample (5.2\%) consisted of highly frequent recidivists, averaging over 19 police contacts during the 5-year follow-up. Boys on this trajectory-which was labeled 'High'-were disproportionately registered for violent offences.

Next, each boy was assigned to a trajectory based on his maximum posterior group membership probability score in

\footnotetext{
${ }^{5}$ Other fit criteria, like the BIC Log Bayes Factor Approximation and OCC also indicated the model to fit the data well.
} 
Frequency trajectory

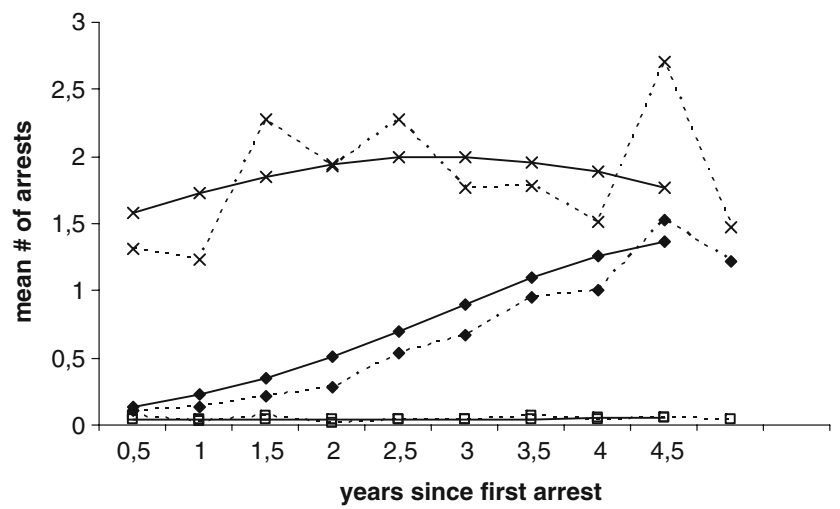

\begin{tabular}{|c|c|c|c|c|c|}
\hline \multicolumn{6}{|c|}{$\begin{array}{l}\longrightarrow \text { group } 1(64.8 \%) \longrightarrow \text { group } 2(30.0 \%) \longrightarrow \text { group } 3(5.2 \%) \\
\cdots-\text { group } 1(\mathrm{obs}) \\
\cdots\end{array}$} \\
\hline \multirow[t]{6}{*}{ \# of groups } & $\mathrm{BIC}$ & & $2 \log (\mathrm{b} 10)$ & Trajectory & OCC $^{1}$ \\
\hline & 1 & -1714.75 & & Group 1 & 6,65 \\
\hline & 2 & -1565.96 & 297.58 & Group 2 & 18,91 \\
\hline & 3 & -1532.10 & 67.72 & Group 3 & 195,26 \\
\hline & 4 & -1542.80 & -21.40 & & \\
\hline & 5 & -1545.84 & -6.08 & & \\
\hline
\end{tabular}

1. A value of $2 \log (\mathrm{b} 10)>10$ and an OCC of $>5$ indicate high assignment accuracy

Fig. 1 Recidivism trajectories

order to create profiles for the 'average' individual following a trajectory characterized by each group. The mean level of offending severity was 2 (minor offending) in all three trajectory groups. However, on average, low level re-offenders peaked at a severity of 2 , escalating offenders peaked at a severity of 3 (moderate offending), and high level re-offenders peaked at a severity of 4 (serious offending) during their offending career.

We then fitted a group-based model using the combined frequency-seriousness measure of offending as the response variable. As was the case with the frequency only model, the BIC criterion indicated that a three-group model best fitted the data (Fig. 1 and Table 1). In the frequencyseriousness model, the average posterior probability of class membership for this three-class solution ranged from 0.87 to 0.94 , indicating a good model fit. Although group
Frequency-seriousness trajectory

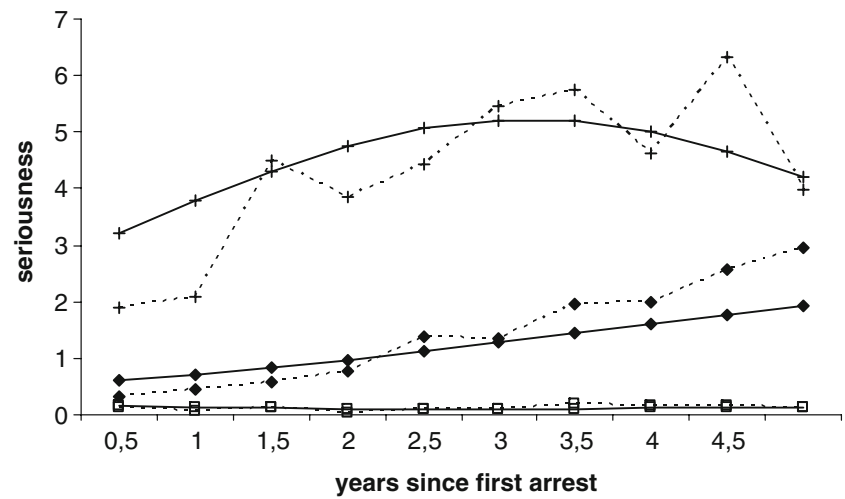

\begin{tabular}{|c|c|c|c|c|c|}
\hline \multicolumn{6}{|c|}{ 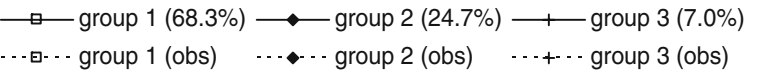 } \\
\hline \# of groups & \multicolumn{2}{|c|}{ BIC } & $2 \log (\mathrm{b} 10)$ & Trajectory & $\mathrm{OCC}^{1}$ \\
\hline & 1 & -2310.89 & & Group 1 & 7,78 \\
\hline & 2 & -2128.41 & 364.96 & Group 2 & 22,01 \\
\hline & 3 & -2085.18 & 86.46 & Group 3 & 226,74 \\
\hline & 4 & -2108.18 & -46.00 & & \\
\hline & 5 & -2108.80 & -1.24 & & \\
\hline
\end{tabular}

size differed slightly compared to the frequency-only model, similarly shaped trajectories were identified in the frequency-seriousness model: a low level $(68.3 \%)$, an escalating $(24.7 \%)$, and a high level $(7.0 \%)$ re-offender trajectory. Mean frequencies were similar in the combined frequency-seriousness trajectories as compared to the frequency-only trajectories, as were offence type distributions. However, including seriousness into the response variable resulted in an increase of the mean seriousness level of offending in the high group from level 2 to level 3 (Table 1).

The identification of similarly shaped trajectories does not necessarily imply that all individuals stayed in the same trajectory when taking into account seriousness in addition to frequency of offending. Although overall most children $(90.6 \%)$ remained in the same trajectory, $16.3 \%$ of the

Table 1 Mean Re-offending Characteristics

\begin{tabular}{|c|c|c|c|c|c|c|}
\hline & \multicolumn{3}{|l|}{ Frequency } & \multicolumn{3}{|c|}{ Frequency $\times$ seriousness } \\
\hline & Low $(n=186)$ & Escalating $(n=86)$ & High $(n=15)$ & Low $(n=196)$ & Escalating $(n=71)$ & High $(n=20)$ \\
\hline Mean number of re-arrests & 0.41 & 7.84 & 19.50 & 0.44 & 7.45 & 19.50 \\
\hline Peak seriousness level & 2 & 3 & 4 & 2 & 3 & 4 \\
\hline Average seriousness & 2 & 2 & 2 & 2 & 2 & 3 \\
\hline Proportion rule breaking & 0.28 & 0.23 & 0.16 & 0.36 & 0.19 & 0.11 \\
\hline Proportion theft & 0.26 & 0.40 & 0.32 & 0.23 & 0.42 & 0.39 \\
\hline Proportion property damage & 0.28 & 0.19 & 0.18 & 0.25 & 0.21 & 0.19 \\
\hline Proportion violence & 0.19 & 0.19 & 0.34 & 0.17 & 0.18 & 0.31 \\
\hline
\end{tabular}

Individuals were assigned to the group of highest probability 
escalating frequency and $13.3 \%$ of the high level frequency group moved to a lower level trajectory group when taking into account seriousness. These were children who offended at a relatively frequent but mostly non-serious level. Finally, $8.1 \%$ of the escalators in the frequency-only model moved to the high level re-offending trajectory when seriousness was included in the response variable, indicating that these children-though infrequently-were committing relatively serious offences at a young age.

\section{Predictors of Re-offending Trajectories}

Compared to the total population of 7-12 year olds in the three studied police regions, first time arrestees were relatively more often residing in highly urbanized neighborhoods $(60.3 \%$ versus $51.4 \%)$, low SES neighborhoods $(62.8 \%$ versus $39.2 \%)$, and were more often of non-Western origin ( $46.2 \%$ versus $19.2 \%)$. The overrepresentation of non-Western children it is not solely caused by more nonWestern children residing in highly urbanized regions as within highly urbanized neighborhoods non-Western offenders are relatively overrepresented as well $(64.1 \%$ versus $28.9 \%$ ).
Table 2 shows the prevalence of the different risk factors by trajectory group. For the frequency-only model, significant group differences were found in SES neighborhood status $\left(\chi^{2}=8.882(2), p<0.05\right.$, mean age of onset $(F=7.128$ (2), $p<0.01)$, and the presence of family members as cooffenders at the initial offence $\left(\chi^{2}=11.578(2), p<0.01\right)$. Post hoc group comparisons revealed that escalators more often resided in low SES neighborhoods, were older at first arrest, and less often had family members as co-offenders at the initial offence than children in the low re-offender trajectory group. Post hoc analyses also showed a difference between children in the high trajectory group and the other two trajectory groups in type of initial offence. For the combined seriousness-frequency model, significant group differences were found in SES neighborhood status $\left(\chi^{2}=6.925(2), p<0.05\right)$, mean age of first arrest $(F=5.722$ (2), $p<0.01)$, the presence of family members as cooffenders at the initial offence $\left(\chi^{2}=6.720(2), p<0.05\right)$, and notification of parents by the police after first arrest $\left(\chi^{2}=8.524(2), p<0.05\right)$. Although age of onset and prevalence of low SES status were similar in both escalating and high level re-offenders, post-hoc comparisons were only significant for the escalators compared to the low level re-

Table 2 Prevalence of Risk Factors by Trajectory Group

\begin{tabular}{|c|c|c|c|c|c|c|c|c|c|c|}
\hline & \multicolumn{5}{|c|}{ Frequency } & \multicolumn{5}{|c|}{ Frequency $\times$ seriousness } \\
\hline & $\begin{array}{l}\text { Low } \\
(n=186)\end{array}$ & $\begin{array}{l}\text { Escalating } \\
(n=86)\end{array}$ & $\begin{array}{l}\text { High } \\
(n=15)\end{array}$ & & $\begin{array}{l}\text { Post } \\
\text { hoc }\end{array}$ & $\begin{array}{l}\text { Low } \\
(n=196)\end{array}$ & $\begin{array}{l}\text { Escalating } \\
(n=71)\end{array}$ & $\begin{array}{l}\text { High } \\
(n=20)\end{array}$ & & $\begin{array}{l}\text { Post } \\
\text { hoc }\end{array}$ \\
\hline \multicolumn{11}{|l|}{ Individual characteristics (\%) } \\
\hline Non-Dutch & 43.8 & 54.1 & 60.0 & & & 44.7 & 51.4 & 65.0 & & \\
\hline Low SES & 56.5 & 74.4 & 73.3 & $* *$ & $\mathrm{a}$ & 57.7 & 74.6 & 70.0 & $* *$ & a \\
\hline High urban & 56.5 & 65.9 & 57.1 & & & 58.8 & 60.0 & 63.2 & & \\
\hline Age at onset & 9.8 & 10.5 & 10.8 & $* * *$ & $\mathrm{a}$ & 9.8 & 10.5 & 10.4 & $* * *$ & $\mathrm{a}$ \\
\hline \multicolumn{11}{|l|}{ Characteristics fist police contact (\%) } \\
\hline Type of offence & & & & NA & $\mathrm{bc}$ & & & & NA & \\
\hline Mischief & 21.5 & 24.4 & 20.0 & & & 21.9 & 25.4 & 15.0 & & \\
\hline Theft & 22.6 & 19.8 & 53.3 & & & 21.9 & 22.5 & 40.0 & & \\
\hline Violence & 17.7 & 22.1 & 20.0 & & & 19.4 & 18.3 & 20.0 & & \\
\hline Property damage & 38.2 & 33.7 & 6.7 & & & 36.7 & 33.8 & 25.0 & & \\
\hline Seriousness & 2.3 & 2.4 & 2.3 & & & 2.4 & 2.3 & 2.4 & & \\
\hline Committed alone & 18.8 & 23.3 & 33.3 & & & 18.4 & 23.9 & 35.0 & & \\
\hline Co-offender family member & 22.0 & 6.1 & 0.0 & $* * *$ & $\mathrm{a}$ & 20.4 & 7.5 & 10.0 & $* *$ & $\mathrm{a}$ \\
\hline Co-offender 4 years or more older & 13.4 & 12.8 & 0.0 & & & 13.3 & 11.3 & 10.0 & & \\
\hline \multicolumn{11}{|c|}{ Police follow-up first police contact (\%) } \\
\hline Parents notified & 69.7 & 59.5 & 78.6 & & & 70.1 & 54.3 & 84.2 & $* *$ & $a b$ \\
\hline \multicolumn{11}{|l|}{ Police reaction } \\
\hline None & 34.4 & 32.6 & 20.0 & & & 32.1 & 40.8 & 15.0 & & \\
\hline Reprimand & 38.2 & 37.2 & 46.7 & & & 39.8 & 35.2 & 35.0 & & \\
\hline Arrest & 27.4 & 30.2 & 33.3 & & & 28.1 & 23.9 & 50.0 & & \\
\hline Diversion project (STOP) & 4.3 & 10.5 & 6.7 & & & 5.6 & 8.5 & 5.0 & & \\
\hline
\end{tabular}

Individuals were assigned to the group of highest probability to compute prevalence

$N A$ overall tests not available due to low expected count in cells, $a p<0.01$ difference between low and escalating, $b p<0.01$ difference between low and high, $c p<0.01$ difference between escalating and high

${ }^{*} p<0.1 ; * * p<0.05 ; * * *<0.01$ using $\chi^{2}$ for the categorical and ANOVA for the continuous measures 
offenders. Further, compared to parents in the low level group, parents in the escalating group were less often notified while parents in the high level trajectory group were more often notified of the initial arrest.

Table 3 shows results from the multivariate analysis in which risk factors were added to the group-based model. Individual predictors differentiated somewhat better among the trajectory groups when using the combined frequency-seriousness outcome measure than when using the frequency-only outcome measure. For both outcome measures, escalating re-offenders were older and more often resided in low SES neighborhoods compared to low level reoffenders - the latter more outspoken in the frequencyseriousness model. High level re-offenders only differed from low level re-offenders in the combined frequencyseriousness trajectory in that they were somewhat older and more often of non-Western ethnic background.

Different first offence characteristics differentiated between the low and escalating level offenders in the frequency-only and in the combined frequency-seriousness trajectories (see Table 3). In the frequency-only trajectory, escalators more often committed their first official offence with older co-offenders and without family. In addition, they more often committed property damage compared to rule breaking offences. However, in the combined frequencyseriousness trajectory, the only difference between low level re-offenders and escalators was the higher prevalence of family as co-offenders in the low level trajectory group. Having a family member present was rare in all three groups. It was even non-existent in the high level group, resulting in the substantial standard errors in the model. Regarding differences with the high level re-offenders, in the frequency-only trajectory, first offence characteristics did not differentiate high level offenders from the other two groups, while in the frequency-seriousness trajectory property damage was more common in the high level group compared to the low level and escalating groups.

The intervention by the police after the first offence differentiated well among the frequency-seriousness trajectories, but only poorly for the frequency-only trajectories

Table 3 Coefficients of Risk Factors by Trajectory Group (Low Group is Reference Group)

\begin{tabular}{|c|c|c|c|c|c|c|c|c|c|c|c|}
\hline & \multirow[t]{3}{*}{ Range } & \multicolumn{5}{|c|}{ Frequency } & \multicolumn{5}{|c|}{ Frequency $\times$ seriousness } \\
\hline & & \multicolumn{2}{|c|}{$\begin{array}{l}\text { Escalating } \\
(n=86)\end{array}$} & \multicolumn{2}{|c|}{ High $(n=15)$} & \multirow[t]{2}{*}{$\begin{array}{l}\text { Escalating } \\
\text { versus high }^{\mathrm{a}}\end{array}$} & \multicolumn{2}{|c|}{$\begin{array}{l}\text { Escalating } \\
(n=71)\end{array}$} & \multicolumn{2}{|c|}{ High $(n=20)$} & \multirow[t]{2}{*}{$\begin{array}{l}\text { Escalating } \\
\text { versus high }\end{array}$} \\
\hline & & Coef. & SE & Coef. & $\mathrm{SE}$ & & Coef. & $\mathrm{SE}$ & Coef. & SE & \\
\hline \multicolumn{12}{|c|}{ Individual characteristics } \\
\hline Non-Dutch & $0-1$ & 0.23 & 0.44 & 0.82 & 0.85 & & 0.02 & 0.53 & 1.13 & $0.69^{*}$ & \\
\hline Low SES & $0-1$ & 0.88 & $0.47 *$ & 0.86 & 0.87 & & 1.45 & $0.57 * * *$ & -0.02 & 0.74 & \\
\hline High urban & $0-1$ & 0.07 & 0.46 & -0.60 & 0.93 & & -0.25 & 0.53 & -1.00 & 0.71 & \\
\hline Age at onset & & 0.52 & $0.16^{* * *}$ & 0.36 & 0.31 & & 0.55 & $0.18 * * *$ & 0.35 & $0.21 *$ & \\
\hline \multicolumn{12}{|c|}{ Characteristics first police contact } \\
\hline \multicolumn{12}{|c|}{ Type of offence } \\
\hline Theft & $0-1$ & -0.58 & 0.69 & 0.98 & 1.15 & & 0.90 & 0.87 & 0.95 & 1.05 & \\
\hline Violence & $0-1$ & 0.53 & 0.78 & 0.98 & 1.28 & & 0.36 & 0.85 & 1.67 & 1.21 & \\
\hline Property damage & $0-1$ & 0.68 & 0.67 & -0.73 & 1.60 & & 0.62 & 0.88 & 1.85 & $1.06^{*}$ & $*$ \\
\hline Seriousness & $1-5$ & -0.03 & 0.29 & -0.36 & 0.50 & & -0.40 & 0.44 & -0.11 & 0.38 & \\
\hline Committed alone & $0-1$ & 0.80 & 0.50 & 0.30 & 0.79 & & 0.78 & 0.55 & 0.72 & 0.63 & \\
\hline $\begin{array}{l}\text { Co-offender family } \\
\text { member }\end{array}$ & $0-1$ & -1.19 & $0.61 * *$ & -24.09 & & & -1.19 & $0.72 *$ & -1.13 & 1.13 & \\
\hline $\begin{array}{l}\text { Co-offender } 4 \text { years } \\
\text { or more older }\end{array}$ & $0-1$ & 1.14 & $0.59 * *$ & -13.54 & & & 0.92 & 0.70 & 0.25 & 0.91 & \\
\hline \multicolumn{12}{|c|}{ Police follow-up first police contact } \\
\hline Parents notified & $0-1$ & -0.74 & 0.46 & 0.15 & 0.88 & & -1.17 & $0.51 * *$ & 0.05 & 0.72 & $*$ \\
\hline \multicolumn{12}{|l|}{ Police reaction } \\
\hline None & Ref & & & & & & & & & & \\
\hline Reprimand & $0-1$ & -0.23 & 0.49 & 0.82 & 1.20 & & -1.09 & $0.61^{*}$ & 2.30 & $1.16^{* *}$ & $* * *$ \\
\hline Arrest & $0-1$ & 0.32 & 0.56 & 0.04 & 1.47 & & -1.47 & $0.73 * *$ & 3.02 & $1.17 * * *$ & $* * *$ \\
\hline $\begin{array}{l}\text { Diversion project } \\
\text { (STOP) }\end{array}$ & $0-1$ & 1.00 & 0.80 & 1.09 & 1.31 & & 1.70 & $0.95 *$ & -0.96 & 1.30 & $*$ \\
\hline
\end{tabular}

$* p<0.1 ; * * p<0.05 ; * * * p<0.01$

${ }^{a}$ Differences between the escalating and high groups were computed using a Wald test. Significance levels are displayed 
(Table 3). In the frequency-seriousness trajectories, the escalating group was characterized by having their parents less often notified and the youths not officially being reprimanded or taken to the police station. On the contrary, escalating re-offenders were more often referred to a voluntary diversion project. Furthermore, compared to both other trajectory groups, high level re-offenders were more often reprimanded and taken to the police station, and their parents were more often notified by the police.

\section{Co-occurring Detrimental Outcomes}

As Table 4 shows, the more serious the trajectory, the more common other adverse outcomes were, with highest rates of adverse outcomes in the high re-offender trajectory group. In the frequency-only trajectory, over half of the high reoffender trajectory group was known to the police for street violence victimization or for status offences such as truancy, running away, or substance use. One third was registered in relation to domestic problems, and over one quarter for witnessing street violence. In the combined frequency-seriousness model, prevalence rates were lower, but remained higher than those of the low level and the escalating trajectory groups (see Table 4).

Child Welfare Agency records paint a similar picture, with high level re-offenders showing higher rates of overall problematic functioning than both other trajectory groups and the escalating trajectory group showing higher rates than the low level re-offender trajectory group. In contrast to the police records, there was little difference in prevalence rates of Child Welfare Agency records among the trajectory groups as identified by frequency-only or by the combined frequency-seriousness measure of re-offending. Over half of the boys in the high level offender group were known to the Child Welfare Agency because of individual child or family problems not directly related to the offending. One third was placed under custody of a guardian, while one fifth was placed outside the home at some point during follow-up. Although prevalence rates were lower in the escalating and low re-offender trajectory groups, they were still high compared to the normal Dutch population, as the prevalence rate of juvenile custody placement in the general population is $0.07 \%$ (Ploegmakers et al. 2005).

\section{Discussion}

Examining recidivism in juveniles with a first police arrest prior to the age of 12 , this study identified three reoffending trajectories: low level, escalating, and high level re-offenders. These three trajectories were independently identified with two different re-offending outcomes, one focusing on frequency only and the other on frequency combined with seriousness. Despite the high-risk nature of our sample nearly two-thirds of the sample either desisted completely or only re-offended at a sporadic and non-serious level after their initial police contact. This finding greatly qualifies the popular notion that an early start inevitably results in a prolonged and escalating criminal career. The remaining third of the sampled boys were registered repeatedly over the next 5 years, with a small proportion of boys recidivating at a very high frequency/seriousness level-averaging four police registrations per year.

Within the limits of the follow-up period of the study, the high level re-offending trajectory seems to resemble Moffitt's persistent offender group and Patterson's early starter group in frequency, seriousness and proportion of violent offences. Surprisingly, the prevalence rates of high level re-offenders in this study were similar to the

Table 4 Prevalence of other Detrimental Outcomes by Trajectory Group

\begin{tabular}{|c|c|c|c|c|c|c|c|c|c|c|}
\hline & \multicolumn{5}{|c|}{ Frequency } & \multicolumn{5}{|c|}{ Seriousness-frequency } \\
\hline & $\begin{array}{l}\text { Low } \\
(n=186)\end{array}$ & $\begin{array}{l}\text { Escalating } \\
(n=86)\end{array}$ & $\begin{array}{l}\text { High } \\
(n=15)\end{array}$ & $\chi^{2}(d f=2)$ & & $\begin{array}{l}\text { Low } \\
(n=196)\end{array}$ & $\begin{array}{l}\text { Escalating } \\
(n=71)\end{array}$ & $\begin{array}{l}\text { High } \\
(n=20)\end{array}$ & $\chi^{2}(d f=2)$ & \\
\hline \multicolumn{11}{|l|}{ Police record } \\
\hline Home risk & 2.2 & 14.0 & 33.3 & $27.877 * * *$ & $a, b, c$ & 3.1 & 15.5 & 20.0 & $16.977 * * *$ & $\mathrm{a}, \mathrm{b}, \mathrm{c}$ \\
\hline Child risk & 3.2 & 16.3 & 53.3 & $45.518 * * *$ & $a, b, c$ & 3.6 & 19.7 & 35.0 & $30.995 * * *$ & $a, b, c$ \\
\hline Victim violence on street & 9.1 & 24.4 & 53.3 & $26.566^{* * *}$ & $a, b, c$ & 9.2 & 28.2 & 40.0 & $23.137 * * *$ & $a, b, c$ \\
\hline Witness violence on street & 3.8 & 14.0 & 26.7 & $15.754 * * *$ & $\mathrm{a}, \mathrm{b}, \mathrm{c}$ & 4.1 & 15.5 & 20.0 & $13.396 * * *$ & $a, b, c$ \\
\hline \multicolumn{11}{|l|}{ Child welfare agency records } \\
\hline Civil file & 3.2 & 12.8 & 53.3 & $46.397 * * *$ & $a, b, c$ & 2.6 & 12.7 & 55.0 & $64.646 * * *$ & $a, b, c$ \\
\hline Placed under custody & 3.2 & 9.8 & 40.0 & $29.852 * * *$ & $a, b, c$ & 3.1 & 11.8 & 31.6 & $24.455 * * *$ & $a, b, c$ \\
\hline Out home placement & 1.1 & 8.1 & 20.0 & $17.211 * * *$ & $a, b, c$ & 1.0 & 8.5 & 20.0 & $20.610^{* * *}$ & $\mathrm{a}, \mathrm{b}, \mathrm{c}$ \\
\hline
\end{tabular}

Individuals were assigned to the group of highest probability to compute prevalence

$a p<0.01$ difference between low and escalating, $b \quad p<0.01$ difference between low and high, $c p<0.01$ difference between escalating and high ${ }^{*} p<0.1 ; * * p<0.05 ; * * * p<0.01$ 
prevalence rates found in the general population. One reason for this could be that the escalating group distinguished in the current sample would also have been regarded as high level offenders in the general population. The escalating group accelerated in official offending around age 12, an age which is still regarded as 'early onset' in most studies and theories. Contrary to findings in other studies we did not identify a desisting trajectory that first peaked in childhood offending frequency before desisting in adolescence. Still, a non-trivial proportion of boys in the low level trajectory group may have actually offended at a substantial level during childhood while only being arrested once or twice. Not getting arrested for childhood offending may be more likely than not getting arrested for adolescent offending as with age offending behavior is increasingly displayed outside the home (Patterson 1996; Loeber et al. 1998).

There may have been several reasons for the limited prognostic value of the offence related and socio-demographic characteristics. First, the limited size of the high reoffending group may have contributed to this. For instance, in line with theories predicting social disadvantage to be related to the level of re-offending in early onset offenders, the prevalence of low SES status was high in both the high level and escalating re-offender trajectory groups. Yet, only the difference with the larger escalating group reached statistical significance. Second, this study only included risk factors readily known to the police. It might be, as Moffitt's typology suggests, that intrinsic risk factors, rather than demographics, are better predictors of prolonged delinquency in early onset arrestees. The high prevalence of domestic problems and Child Welfare Agency involvement in the high risk group found in this study might be interpreted as indicative of such individual difficulties. However, since no childhood measures of individual impairment were included in the current study the causal direction of this association remains unidentified. Finally, the limited predictive value of the measured risk factors may represent the actual limited power of characteristics measured in childhood to predict offending in adolescence. This would be in line with Sampson and Laub's theory stressing the plasticity of development, and thereby the unpredictability of offending careers.

Regardless of the theoretical implications, for daily practice our findings stress the difficulty of predicting who will desist and who will persist based on characteristics generally known to the police. Therefore, future study into this specific high risk, early onset group is warranted. First, to further test the discriminating value of existing developmental theories in identifying different re-offending trajectories within this group, and second, to contribute to providing professionals with reliable tools to help direct their efforts to those youths most in need.
Notwithstanding the limited predictive value of the potential risk factors, the police did react more severely at the initial offence to boys in the high level re-offending group. One could argue that the first police reaction triggers a negative spiral increasing the likelihood of subsequent offending. On the other hand, it is also likely that the reaction of the police is based on other information than the offence itself. For instance, high-risk boys may have more often reacted indifferently or even disrespectfully to the police encounter during prior encounters. In addition, some of the boys or their families may have already been known to the police because of other incidents in the familysomething our co-occurrence analysis seems to supportresulting in more severe follow-up by the police following a first arrest. If this is the case, more detailed study is needed to find out what exactly causes the police to react more severely to children who are at higher risk of re-offending, in an effort to optimize this screening ability.

Finally, all the children in our sample experienced high prevalence rates of non-delinquent detrimental outcomes. Compared to the Dutch population a disproportionate number of youths in our sample - especially those on escalating or high level offending trajectories - were victimized, faced substantial domestic problems, and eventually became known to the Child Welfare Agency. This indicates that early onset offenders face substantial difficulties limiting their chances of healthy development into adolescence. It also stresses the need to focus on children with an early police encounter in order to offer them the appropriate care.

\section{Limitations}

Like any dataset, the one used here has limitations that need to be considered. First, the data only pertain to officially registered delinquent acts. While neither official data nor self-reports constitute a true measure of delinquency, selfreport studies have the advantage that they can monitor a wider array of antisocial behavior, including behavior that is less likely to result in a police contact. On the other hand, official data may be more reliable regarding the timing of offences as well as the occurrence of more serious offences. In contrast to conviction records, police records also include less serious offences that do not end up in court. Second, the current study used an aggregated offence measure that did not distinguish between offence types. Different types of offences have been found to be marked by different developmental pathways (Barker et al. 2007). As a result factors specifically predictive for certain offense types may not have emerged. Third, the follow-up period of the study was relatively short. Future studies should include a longer follow-up period to study childhood onset offending trajectories into adulthood. Last, self-report studies often include information on other characteristics 
assumed to be associated with persistent delinquency, like psychological and family risk factors. However, this kind of information is unlikely to be available to the police. Therefore, for daily practice, it is important to be able to predict delinquency trajectory outcomes based on information that is readily known to the police.

Open Access This article is distributed under the terms of the Creative Commons Attribution Noncommercial License which permits any noncommercial use, distribution, and reproduction in any medium, provided the original author(s) and source are credited.

\section{References}

Barker, E. B., Séguin, J. R., Raskin White, E., Bates, M. E., Lacourse, E., Carbonneau, R., et al. (2007). Developmental trajectories of male physical violence ant theft; relations to neurocognitive performance. Archives of General Psychiatry, 64, 592-599. doi:10.1001/archpsyc.64.5.592.

Broidy, L. M., Nagin, D. S., Tremblay, R. E., Bates, J. E., Brame, B., Dodge, K. A., et al. (2003). Developmental trajectories of childhood disruptive behaviors and adolescent delinquency: a six-site, cross-national study. Developmental Psychology, 39, 222-245. doi:10.1037/0012-1649.39.2.222.

Chung, I. J., Hill, K. G., Hawkins, J. D., Gilchrist, L. D., \& Nagin, D. S. (2002). Childhood predictors of offense trajectories. Journal of Research in Crime and Delinquency, 39, 60-90.

den Heeten, J., \& Verweij, A. O. (1993). Identification and registration of ethnic background: manual for registration and policy. [Identificatie en registratie van etnische herkomst; een handleiding voor registratie en beleid.]. Den Haag: Vereniging van Nederlandse Gemeenten.

Espiritu, R. C., Huizinga, D., Crawford, A. M., \& Loeber, R. (2001). Epidemiology of self-reported delinquency. In R. Loeber, \& D. P. Farrington (Eds.), Child delinquents: development, intervention and service needs (pp. 47-66). Thousand Oaks, CA: Sage.

Farell, A. D., Sullivan, T. N., Esposito, L. E., Meyer, A. L., \& Valois, R. F. (2005). A latent growth curve analysis of the structure of aggression, drug use, and delinquent behaviors and their interrelations over time in urban and rural adolescents. Journal of Research on Adolescence, 15, 179-204. doi:10.1111/j.1532-7795.2005.00091.x.

Fergusson, D. M., \& Horwood, L. J. (2002). Male and female offending trajectories. Development and Psychopathology, 14, 159-177. doi:10.1017/S0954579402001098.

Gottfredson, M. R., \& Hirschi, T. (1990). A general theory of crime. Stanford, CA: Stanford University Press.

Hoeve, M., Blokland, A. A. J., Semon-Dubas, J., Loeber, R., Gerris, J. R. M., \& Van der Laan, P. (2007). Trajectories of delinquency and parenting styles. Journal of Abnormal Child Psychology, 36, 223-235. doi:10.1007/s10802-007-9172-x.

Jones, B. L., \& Nagin, D. S. (2007). Advances in group-based trajectory modeling and an SAS procedure for estimating them. Sociological Methods \& Research, 35, 542-571. doi:10.1177/ 0049124106292364.

Knol, F. A. (1998). From high to low, from low to high: the social and environmental development of neighbourhoods [Van hoog naar laag, van laag naar hoog: De sociaalruimtelijke ontwikkeling van wijken.] SCP-Cahier 152. Den Haag: SCP.
Krohn, M. D., Thornberry, T. P., Rivera, C., \& LeBlanc, M. (2001). Later delinquency careers. In R. Loeber, \& D. P. Farrington (Eds.), Child delinquents: development, intervention and service needs (pp. 67-94). Thousand Oaks, CA: Sage.

Lahey, B. B., \& Waldman, I. D. (2005). A developmental model of the propensity to offend during childhood and adolescence. In D. P. Farrington (Ed.), Integrated developmental \& life-course theories of offending (pp. 15-50). New Brunswick: Transaction.

Lauritsen, J. L., Sampson, R. J., \& Laub, J. H. (1991). Addressing the link between offending and victimization among adolescents. Criminology, 29, 265-291. doi:10.1111/j.1745-9125.1991. tb01067.x.

Lipsey, M. W., \& Derzon, J. H. (1998). Predictors of violent or serious delinquency in adolescence and early adulthood: a synthesis of longitudinal research. In R. Loeber, \& D. P. Farrington (Eds.), Serious and violent juvenile offenders: risk factors and successful interventions (pp. 313-345). Thousand Oaks, CA: Sage.

Loeber, R., DeLamatre, M., Keenan, K., \& Zang, Q. (1998). A prospective replication of developmental pathways in disruptive and delinquent behavior. In R. Cairns, L. Bermand, \& J. Kagan (Eds.), Methods and models for studying the individual (pp. 185215). Thousand Oaks, CA: Sage.

Loeber, R., \& Farrington, D. P. (2000). Young children who commit crime: epidemiology, developmental origins, risk factors, early interventions, and policy implications. Development and Psychopathology, 12, 737-762. doi:10.1017/S0954579400004107.

Loeber, R., \& Farrington, D. P. (Eds.). (2001). Child delinquents: development, intervention and service needs. Thousand Oaks, CA: Sage.

Loeber, R., Farrington, D. P., Stouthamer-Loeber, M., \& White, H. R. (2008). Violence and serious theft: risk and promotive factors from childhood to early adulthood. Mahwah, NJ: Erlbaum.

Moffitt, T. E. (1993). Adolescence-limited and life-course-persistent antisocial behavior: a developmental taxonomy. Psychological Review, 100, 674-701. doi:10.1037/0033-295X.100.4.674.

Moffitt, T. E., Caspi, A., Harrington, H., \& Milne, B. J. (2002). Males on the life-course-persistent and adolescence-limited antisocial pathways: follow-up at age 26 years. Development and Psychopathology, 14, 179-207. doi:10.1017/S0954579402001104.

Nagin, D. S. (1999). Analyzing developmental trajectories: a semiparametric, groupbased approach. Psychological Methods, 42, 139-157. doi:10.1037/1082-989X.4.2.139.

Nagin, D. S. (2005). Group-based modeling of development over the life course. Cambridge, MA: Harvard University Press.

Nagin, D. S., \& Land, K. C. (1993). Age, criminal careers, and population heterogeneity: specification and estimation of a nonparametric, mixed Poisson model. Criminology, 31, 327362. doi:10.1111/j.1745-9125.1993.tb01133.x.

Nagin, D., \& Tremblay, R. E. (1999). Trajectories of boys' physical aggression, opposition, and hyperactivity on the path to physically violent and nonviolent juvenile delinquency. Child Development, 70, 1181-1196. doi:10.1111/1467-8624.00086.

Odgers, C. L., Caspi, A., Broadbent, J. M., Dickson, N., Hancox, R. J., Harrington, H., et al. (2007). Prediction of differential adult health burden by conduct problem subtypes in males. Archives of General Psychiatry, 64, 476-484. doi:10.1001/archpsyc. 64.4.476.

Patterson, G. R. (1996). Some characteristics of a developmental theory of early-onset delinquency. In M. F. Lenzenweger, \& J. J. Haugaard (Eds.), Frontiers of developmental psychopathology (pp. 167-320). Hillsdale, NJ: Erlbaum.

Patterson, G. R., Forgatch, M. S., Yoerger, K. L., \& Stoolmiller, M. (1998). Variables that initiate and maintain an early-onset trajectory for juvenile offending. Development and Psychopathology, 10, 531-547. doi:10.1017/S0954579498001734. 
Piquero, A. (2008). Taking stock of developmental trajectories of criminal activity over the life course. In A. M. Liberman (Ed.), The long view of crime (pp. 23-78). New York: Springer.

Piquero, A. R., \& Chung, H. L. (2001). On the relationships between gender, early onset, and the seriousness of offending. Journal of Criminal Justice, 29, 189-206. doi:10.1016/S0047-2352(01)00084-8.

Ploegmakers, M. J. H., de Smet, J. M. A., Wiebes, P. E., \& van Dam, C. L. (2005). Brancherapporten VWS. Den Haag: VWS.

Raine, A., Moffitt, T. E., Caspi, A., Loeber, R., Stouthamer-Loeber, M., \& Lynam, D. (2005). Neurocognitive impairments in boys on the life-course persistent antisocial path. Journal of Abnormal Psychology, 114, 38-49. doi:10.1037/0021-843X.114.1.38.

Sampson, R. J., \& Laub, J. H. (2005). A life-course view on the development of crime. The Annals of the American Academy of Political and Social Science, 602, 12-45. doi:10.1177/ 0002716205280075.

Snyder, H. N. (2001). Epidemiology of official offending. In R. Loeber, \& D. P. Farrington (Eds.), Child delinquents: development, intervention and service needs (pp. 25-46). Thousand Oaks, CA: Sage.

Social and Cultural Planning Office of the Netherlands (SCP).(2002). Ranking of socio-economic status based on postal codes in the
Netherlands [Rangorde naar sociale status van postcodegebieden in Nederland]. Retrieved from http://www.scp.nl/onderzoek/ statusscores/.

Statistics Netherlands. (2001). WebSelector: bevolking/status/land van herkomst. Retrieved from http://statline.cbs.n1/StatWeb/.

Statistics Netherlands. (2006). WebSelector: Nederland regionaal/ kerncijfers/ kerncijfers wijken en buurten 2001/ stedelijkheid. Retrieved from http://statline.cbs.nl/StatWeb/.

Stouthamer-Loeber, M., Loeber, R., Stallings, R., \& Lacourse, E. (2008). Desistance from and persistence in offending. In R. Loeber, D. P. Farrington, M. Stouthamer-Loeber, \& H. R. White (Eds.), Violence and serious theft: risk and promotive factors from childhood to early adulthood. Mahwah, NJ: Erlbaum.

Thornberry, T. P., \& Krohn, M. D. (2001). The development of delinquency: an interactional perspective. In S. O. White (Ed.), Handbook of youth and justice (pp. 289-305). New York: Plenum.

Tolan, P. H., \& Gorman-Smith, D. (1998). Development of serious and violent offending careers. In R. Loeber, \& D. P. Farrington (Eds.), Serious and violent juvenile offenders: risk factors and successful interventions (pp. 313-345). Thousand Oaks, CA: Sage. 